\title{
A Descriptive Study to Assess the Knowledge, Attitude, and Practice on Carbonated Soft Drinks and Their Effect on Health among Teenagers in Selected Educational Institutions of Mangalore
}

\author{
Indumathy \\ Tutor (Ph.D Scholar), VMMC \& SJH College of Nursing. \\ DOI: https://doi.org/10.24321/2454.325X.201816
}

\section{Abstract}

Introduction: The Indian culture has accepted the habit of drinking carbonated soft drinks. As flavored carbonated beverages gained popularity, many people especially teenagers are used to the consumption of large quantities of soft drinks all through the day neglecting their normal food habits.

Aim: To assess the knowledge, attitude and practice (KAP) on carbonated soft drinks and their effect on health among teenagers.

Materials and Methods: 100 students in the age group of 13-19 years were included in the study. A structured questionnaire was used to measure knowledge, 3-point Likert's scale was used to find attitude and a check list was used to assess the practice.

Results: Among teenagers, $13.8 \%$ had adequate knowledge, $23.55 \%$ had favorable attitude towards carbonated soft drinks and their effect on health. The favorable practice was shown by $28 \%$ of teenagers.

Conclusion: Health education and primordial prevention would be the best way to create awareness and to adopt healthy life style and combat the problems associated with carbonated soft drink consumption among teenagers.

Keywords: Soft drinks, Life style, Primordial prevention, Teens

\section{Introduction}

"To eat is a necessity, but to eat intelligently is an art"

Food is at the heart of our well-being and is central to maintain good health. We have to take good care of our body because it is a vehicle to transport us from one place to another and enable us to do the things that we dream of doing. Food, health and education are the three most important ingredients of our lives. The leading trend in functional food ingredients can impact our health and life style.

Nowadays the consumption of soft drinks is much favored by every generation. No sector is left unaffected by their influence. People are consuming soft drinks almost every day without even knowing their ill-effects, and thus harm their own health.

E-mail Id: indumathy.bhoopathy@gmail.com Orcid Id: https://orcid.org/0000-0001-7757-7893

How to cite this article: Indumathy. A Descriptive Study to Assess the Knowledge, Attitude, and Practice on Carbonated Soft Drinks and Their Effect on Health among Teenagers in Selected Educational Institutions of Mangalore. Int J Preven Curat Comm Med 2018; 4(3): 8-11. 
Recent studies have shown that teenagers are the group who are consuming the soft drinks regularly. In all the controversies over what the soft drinks are and their ill effects to health, the teenagers must not have paid attention to avoid them. They yield to occur health problems to them.

\section{Need for the Study}

According to American Health Centre of Saina, soft drinks are enormously popular beverages consisting primarily of carbonated water, sugar, and flavoring. Many countries enjoy the sweet sparkling soda with an unusual consumption of more than 34 billion gallons.

Soft drink manufacturers have been quick to respond to consumer preferences. In 1962, diet colas were introduced in response to the fashion of thinness for women. In the 1980 s, the growing health consciousness of the country led to creation of caffeine-free and low-sodium soft drinks. New flavors of carbonated soft drinks constantly appeared on the market.

High prevalence of exposure and excessive consumption of soft drinks may represent an emerging public health problem. Hence this study was considered as an eye opener for teenagers in whom awareness regarding carbonated soft drinks and related problems are included.

\section{Statement}

A descriptive study to assess the knowledge, attitude, and practice on carbonated soft drinks and their effect on health among teenagers in selected educational institutions of Mangalore.

\section{Objectives}

- $\quad$ To assess the knowledge, attitude, and practice (KAP) on carbonated soft drinks and their effects on health among teenagers.

- To create awareness regarding carbonated soft drinks and their effect on health among teenagers.

\section{Review of Literature}

The study has been reviewed under following sections:

Section A: Literature related to carbonated soft drinks conception among teenagers

Section B: Literature related to effects of carbonated soft drinks on health of teenagers

\section{Research Methodology}

A study was carried out among students of schools and colleges in Mangalore, India. The target population for this study was 100 students. In this study, a knowledge questionnaire consists of part 1 and part 2, namely, carbonated soft drinks and effects on health. Modified 3-point Likert's scale to assess the attitude and a check list to assess their practice. Based on the total score, knowledge, attitude and practice were graded as:

- Excellent knowledge, favorable attitude and favorable practice the score is: $\geq 80 \%$.

- Good knowledge, moderately favorable attitude and moderately favorable practice the score is: $51-79 \%$.

- Poor knowledge, unfavorable attitude and unfavorable practice the score is: $\leq 50 \%$.

The questionnaire was checked for validity. The aims and objectives were explained to all the students before starting the study, and consent was obtained from all the students prior to the beginning of the study. The study was approved by the ethical clearance committee of the institution. Permission was sought from the concerned authority.

\section{Data Analysis and Interpretation}

- Appropriate descriptive and inferential statistics methods were used.

- Descriptive statistics that were used include frequencies, percentage, mean, median, range and standard deviation.

- The level of significance was $p<0.05$. 


\section{Section A}

Table 1.Frequency and Percentage Distribution of Demographic Variables of Teenagers

\begin{tabular}{|c|c|c|c|}
\hline S. No. & Demographic Variables & Frequency & Percentage \\
\hline 1 & $\begin{array}{c}\text { Age of the teenagers } \\
13 \text { to } 15 \text { years } \\
15+\text { to } 17 \text { years } \\
17+\text { to } 19 \text { years }\end{array}$ & $\begin{array}{l}60 \\
22 \\
18\end{array}$ & $\begin{array}{l}60 \\
22 \\
18\end{array}$ \\
\hline 2 & $\begin{array}{c}\text { Present educational level } \\
\text { High school level } \\
\text { Higher secondary level } \\
\text { College level }\end{array}$ & $\begin{array}{l}40 \\
20 \\
40\end{array}$ & $\begin{array}{l}40 \\
20 \\
40\end{array}$ \\
\hline 3 & $\begin{array}{l}\text { Family income per month } \\
\text { Below Rs. } 10,000 \\
\text { Rs. } 10000 \text { to Rs. } 20000 \\
\text { Above Rs. } 20000\end{array}$ & $\begin{array}{l}38 \\
42 \\
20\end{array}$ & $\begin{array}{l}38 \\
42 \\
20\end{array}$ \\
\hline 4 & $\begin{array}{l}\text { Type of family they belong to } \\
\text { Nuclear } \\
\text { Joint } \\
\text { Others (single and separated) }\end{array}$ & $\begin{array}{l}64 \\
24 \\
12\end{array}$ & $\begin{array}{l}64 \\
24 \\
12\end{array}$ \\
\hline 5. & $\begin{array}{c}\text { Sources of health information } \\
\text { Mass media } \\
\text { Family members and relatives } \\
\text { Health agency }\end{array}$ & $\begin{array}{l}16 \\
66 \\
18\end{array}$ & $\begin{array}{l}16 \\
66 \\
18\end{array}$ \\
\hline
\end{tabular}

\section{Section B}

Table 2.Association of Knowledge Attitude and Practice on Carbonated Soft Drinks and Their Effect on Health Among Teenagers

\begin{tabular}{|c|c|c|c|c|c|c|}
\hline $\begin{array}{c}\text { Demographic } \\
\text { Variables }\end{array}$ & Adequate & $\begin{array}{c}\text { Moderately } \\
\text { Adequate }\end{array}$ & Inadequate & Chi-Square Value & df & $\mathrm{p}$-value \\
\hline Knowledge & $13.8 \%$ & $35.82 \%$ & $50.37 \%$ & $7.19^{*}$ & 09 & $\mathrm{p}<0.05^{*}$ \\
\hline Attitude & $23.53 \%$ & $62.14 \%$ & $14.31 \%$ & $0.004^{\prime} \mathrm{NS}^{\prime}$ & 09 & $\mathrm{p}>0.05^{\prime} \mathrm{NS}^{\prime}$ \\
\hline Practice & $28 \%$ & $63 \%$ & $9 \%$ & $0.32^{\prime} \mathrm{NS}^{\prime}$ & 09 & $\mathrm{p}>0.05^{\prime} \mathrm{NS}^{\prime}$ \\
\hline
\end{tabular}

*significant (i.e., $p<0.05$ ) 'NS' not significant (i.e., $p>0.05$ )

\section{Results}

Among teenagers, $13.8 \%$ had adequate knowledge, $23.55 \%$ had favorable attitude towards carbonated soft drinks and their effect on health. The favorable practice was shown by $28 \%$ of teenagers.

It is generally understood that soft drinks, even though they contain a large number of calories, have little nutritional benefit and are known as "empty calories". Soft drinks are composed mostly of filtered water with diet colas containing close to $100 \%$ water. Most of the calories in soft drinks are from refined sugars, and there are no other nutritionally beneficial components in soft drinks. Dr. Charles Best, the discoverer of insulin, claims that teenagers who consume too many soft drinks have cirrhosis of the liver similar to what chronic alcoholics have. A common problem that is associated with consumption of a large number of soft drinks is the increased acid levels throughout the body. All soft drinks are very acidic, but dark colas such as Coke and Pepsi are much more acidic. In the present study the knowledge base of the students regarding the harmful effects of carbonated drinks is not satisfactory.

Majority of students (50\%) did not have adequate level of Knowledge, Attitude and Practice towards carbonated soft drinks and its effects on health.

S. Kishore, P. Aggarwal(2009) reported that the knowledge of the students regarding the ill-effects of the consumption of carbonated drinks is not convincing one. The attitudes of the students are relatively better but their practices are neither preventive nor health promoting. Thus, it is recommended that a holistic approach should be 
incorporated to combat the problems associated with the consumption of carbonated drinks. There is a need of Behavioral Change (BCC) for youngsters.

\section{Conclusion}

Thus to conclude, from the above responses from the students media advertisements and other related factors have led to carbonated drink consumption among students.

Most of them were well aware about the side effects and were willing to stop the consumption of carbonated drinks, if suitable alternatives were available. But they preferred to drink carbonated drinks and fruit juices. It was surprising to note that they were aware of the ill-effects of carbonated beverages, still their consumption of soft drinks was increasing day by day, but they had not experienced any ill effects of consuming carbonated beverages.

Health education would be the best way to adopt a healthy life style and to combat the problems associated with the consumption of carbonated drinks.

\section{Conflict of Interest: None}

\section{References}

1. Denehy J. The health effects of soft drinks. J Sch Nurs 2003; 19: 63-64.

2. Sanchez GA, Fernandez de Preliasco MV. Salivary $p H$ changes during soft drinks consumption in children. Int J Paediatr Dent 2003; 13: 251-57.

3. Moazzez R, Smith BG, Bartlett DW. Oral pH and drinking habit during ingestion of a carbonated drink in a group of adolescents with dental erosion. J Dent 2000; 28: 395-97.

4. Soft drinks - America's other drinking problem. Available at: http://www.kauhawaii.com/softdrinks. html. Accessed on 13 Aug 2008.

5. Wyshak G, Frisch RE. Carbonated beverages, dietary calcium, the dietary calcium/phosphorus ratio, and bone fractures in girls and boys. J Adolesc Health 1994; 15: 210-15.

6. Dental Caries, UCLA School of Dentistry. Available at: http://www.dent.ucla.edu/ce/caries/index.html. Accessed on 13 Aug 2008.

7. Beverages: Liquid Fruits (Technology Source: CFTRI). North East India Databank, CSIR Technology North East India, 2006.

8. Zhai F, Wang H, Du S et al. Prospective study on nutrition transition in China. Nutr Rev 2009; 67(1): S56-61.

9. Kishore S, Aggarwal P, Muzammil K. KAP study about carbonated drinks among Medical and Nursing students at Teaching Hospital Uttarkand. JK science 2009; 11 (4).

Date of Submission: 2018-03-22 Date of Acceptance: 2018-04-30 